\title{
Teores de proteína bruta para bovinos alimentados com feno de tifton 85: consumo e digestibilidades total e parcial ${ }^{1}$
}

\section{Edilane Aparecida da Silva², Telma Teresinha Berchielli ${ }^{3}$, Ricardo Andrade Reis ${ }^{3}$, Juliano José de Resende Fernandes ${ }^{4}$, Kátia Junko Sato ${ }^{5}$, José Mauro Valente Paes ${ }^{6}$}

\author{
1 Parte da tese de Doutorado da primeira autora realizada pelo Programa de Pós-Graduação em Zootecnia da UNESP de Jaboticabal. Projeto \\ financiado pela FAPESP. \\ 2 EPAMIG, Bolsista de Produtividade FAPEMIG. Rua Afonso Rato 1301, Uberaba- MG, CEP: 38001-970. \\ ${ }^{3}$ FCAVIUNESP - Via de Acesso Prof. Paulo Castellane, $s / n$, Jaboticabal-SP. Pesquisador do CNPq \\ ${ }^{4}$ Universidade Federal de Goiás - Escola de Veterinária-DPA. \\ 5 Graduando em Zootecnia na FCAVIUNESP - Jaboticabal-SP. \\ ${ }^{6}$ EPAMIG, Bolsista de Produtividade da FAPEMIG.
}

\begin{abstract}
RESUMO - Avaliou-se o efeito da deficiência de PB na dieta sobre o consumo e as digestibilidades total, ruminal e intestinal dos nutrientes em novilhos mestiços. Os tratamentos consistiram de dietas compostas de feno de tifton 85 (FN) suplementadas com uréia (FNUR), farelo de soja (FNFS) e farelo de glúten de milho-60 (FNGL). Foram utilizados oito novilhos canulados no rúmen e no duodeno, distribuídos em dois quadrados latinos 4 × 4. As digestibilidades ruminal e intestinal dos nutrientes, a produção fecal e o fluxo duodenal de MS foram estimados utilizando-se a fibra em detergente ácido indigestível (FDAi) como indicador, enquanto a digestibilidade total foi determinada pelo método de coleta total de fezes. Os consumos de nutrientes (MS, MO, PB, CT, FDN, FDA e EB) não foram afetados pelos teores de PB das dietas. A digestibilidade aparente total da FDA foi superior para a dieta FNGL $(55,48 \%)$ em relação à FNFS $(41,29 \%)$. As digestibilidades ruminais dos nutrientes, à exceção da PB, não diferiram significativamente entre as dietas, mas a digestibilidade intestinal da PB nas dietas FNFS (66,70\%) e FNGL $(80,25 \%)$ foi superior à observada na dieta FNUR $(57,61 \%)$. O teor de PB das dietas não alterou o consumo (exceto de PB e CNF) e as digestibilidades parciais dos nutrientes (exceto de PB).
\end{abstract}

Palavras-chave: farelo de glúten de milho - 60, farelo de soja, fibra em detergente ácido indigestível, fluxo duodenal, uréia

\section{Effects of crude protein levels on intake and digestibility of nutrients in steers fed Tifton 85 bermudagrass hay supplemented with different protein sources}

\begin{abstract}
Eight crossbred steers fitted with ruminal and duodenal cannulas were randomly assigned to two replicated 4 x 4 Latin squares to evaluate the effects of crude protein (CP) levels on intake and total, ruminal and intestinal digestibility of nutrients. Animals were fed a control diet containing Tifton 85 bermudagrass hay or the control diet supplemented with urea (NPN diet), soybean meal (SBM diet) or corn gluten meal-60 (CGM diet). Indigestible acid detergent fiber was used as the internal marker for measuring duodenal flow of dry matter, ruminal and intestinal digestibility, and fecal output of nutrients. Total fecal collection was used to determine total tract digestibility of nutrients. Nutrient intakes (DM, OM, CP, TC, NDF, ADF, and GE) did not differ among diets. However, apparent total tract digestibility of acid detergent fiber was greater on CGM (55.48\%) than on SBM diet (41.29\%). Except for CP, ruminal digestibilities of all remaining nutrients were similar across diets. Intestinal digestibility of CP on SBM (66.70\%) and CGM diets $(80.25 \%)$ were higher than that on the NPN diet $(57.61 \%)$. It can be concluded that supplementation with different protein sources did not change intake (except for CP and nonfiber carbohydrates) and the partial digestibility of nutrients (except for CP).
\end{abstract}

Key Words: corn gluten meal, duodenal flow, indigestible acid detergent fiber, soybean meal, urea

\section{Introdução}

A digestibilidade de um alimento é estimada, basicamente, pela taxa de utilização de seus nutrientes pelo animal. Essa capacidade de utilização é expressa pelo coeficiente de digestibilidade do nutriente, uma característica do alimento e não do animal (Coelho da Silva \& Leão, 1979). Logo, a digestão consiste em um processo de conversão de macromoléculas do alimento em compostos simples absorvíveis pelo trato gastrintestinal (Van Soest, 1994).

De acordo com Souza et al. (2002), a digestão da fibra é afetada pelo teor de proteína das dietas, principalmente 
aquelas compostas de forragem de baixa qualidade. A deficiência de proteína na dieta limitaria a atividade ruminal afetando a ingestão e a digestibilidade dos nutrientes, visto que as exigências de proteínas pelos ruminantes são atendidas pelos aminoácidos provenientes da proteína microbiana e da proteína dietética não degradada no rúmen. A exigência mínima de nitrogênio ( $\mathrm{N}$ ) para a digestão máxima não é constante, mas muda com a disponibilidade de energia e pode variar com a qualidade do volumoso utilizado.

$O$ fornecimento de fonte de proteína de alta degradabilidade ruminal é fundamental para o crescimento dos microrganismos, pois, juntamente com a energia fermentável no rúmen, define a eficiência de síntese microbiana. A utilização de fontes de baixa degradabilidade ruminal visa ao atendimento das exigências de proteína metabolizável (Branco et al., 2004). No entanto, a utilização de fontes protéicas de rápida degradação ruminal em dietas à base de alimentos com elevado teor da fração $\mathrm{B}_{2}$, ou seja, carboidratos fibrosos potencialmente digestíveis, mas de lenta taxa de degradação ruminal, pode promover elevada fermentação dos aminoácidos e peptídeos resultantes e acúmulo de amônia, que será excretada pela urina. Portanto, a utilização de fontes protéicas de lenta degradação no rúmen pode trazer benefícios e aumentar a eficiência de utilização de nitrogênio pelo animal (Cabral et al., 2004), o que contraria outros resultados na literatura, nos quais verifica-se que a deficiência de proteína degradável no rúmen (PDR) nem sempre afeta a digestibilidade e o consumo dos nutrientes.

O tipo de proteína, de alta ou de baixa degradabilidade ruminal, pode ou não afetar o consumo voluntário. Branco et al. (2004), em estudo com ovinos, utilizaram dietas com diferentes fontes de PDR - farelo de soja (71,18\% PDR), farinha de penas $(66,37 \%$ PDR) e farelo de glúten de milho $(66,23 \%$ PDR ) - e não encontraram diferença na ingestão de MS, MO, PB e FDN. Christensen et al. (1993), trabalhando com fontes de proteína de diferentes degradabilidades no rúmen, também não encontraram efeito da fonte de proteína nos consumos de MS, MO e FDN. Dutra et al. (1997) não encontraram efeito do tipo de proteína no consumo de MS, MO, PB e FDN, fato observado também por Cecava et al. (1990; 1991). Cordes et al. (1988) verificaram que a suplementação com farelo de glúten de milho60 não afetou a digestibilidade do feno; não obstante, a suplementação com milho + uréia reduziu em $12 \%$ a digestibilidade do feno. Cameron et al. (1991) notaram que a digestibilidade aparente da PB aumentou com o teor de $\mathrm{N}$ da ração.

Este estudo foi realizado para avaliar o efeito da deficiência de PDR e/ou PB na dieta sobre o consumo e as digestibilidades total, ruminal e intestinal dos nutrientes em novilhos mestiços.

\section{Material e Métodos}

O experimento foi conduzido no Setor de Avaliação de Alimentos e de Digestibilidade, do Departamento de Zootecnia da Faculdade de Ciências Agrárias e Veterinárias, da UNESP, Campus de Jaboticabal - SP, no período de janeiro a junho de 2001.

Foram utilizados oito novilhos cruzados (Holandês x Zebu) com peso médio de $240 \mathrm{~kg}$, canulados no rúmen e no duodeno, alojados em baias com cochos individuais e bebedouros comuns a duas baias. Todos os animais foram identificados com brincos numerados e foram tratados contra endo e ectoparasitas no início do experimento. Os animais foram pesados no início e ao final de cada período experimental. Os tratamentos consistiram de dietas à base de feno de tifton 85 (FN) suplementadas com uréia (FNUR), farelo de soja (FNFS) e farelo de glúten de milho-60 (FNGL). As dietas, isoprotéicas, foram formuladas com base no teor de $\mathrm{PB}$ dos alimentos e nos requisitos de proteína para mantença, de acordo com o AFRC (1993), com base no N endógeno basal, que inclui perdas urinárias endógenas, parte do $\mathrm{N}$ metabólico fecal e as perdas por descamação de tecidos e pêlos, admitindo-se eficiência de utilização igual a 1. Na dieta com uréia, houve adição de sulfato de amônio na proporção de 9:1 e, para suprir o déficit de energia desse tratamento, utilizou-se o amido de milho. A água foi fornecida à vontade e todos os animais receberam aproximadamente $50 \mathrm{~g}$ de sal mineral juntamente com as rações.

O capim-tifton 85 foi colhido aos 90 dias de rebrota e conservado na forma de feno. $\mathrm{O}$ feno foi triturado em fragmentos de aproximadamente $10 \mathrm{~cm}$ de comprimento e fornecido uma vez ao dia (às $7 \mathrm{~h}$ ), em quantidade para ocorrer $10 \%$ de sobras por animal. Após o período de adaptação à dieta, os animais foram distribuídos em dois quadrados latinos, com quatro tratamentos cada um (FN, FNUR, FNFS, FNGL).

Os carboidratos totais (CT) foram obtidos por meio da equação: $100-(\% \mathrm{~PB}+\% \mathrm{EE}+\%$ cinzas $)$ e os não-fibrosos (CNF) pela diferença entre CT e FDN (Sniffen et al., 1992).

A composição química dos ingredientes e a composição percentual e química das dietas, de acordo com os tratamentos, são indicadas na Tabela 1 .

$\mathrm{O}$ experimento foi dividido em quatro períodos de 27 dias (14 de adaptação dos animais às dietas e sete para as coletas de fezes, digesta duodenal e sobras). Do 190 ao 25 을 dia de cada período experimental, os animais foram alojados em gaiolas de digestibilidade, com piso ripado de madeira, próprias para o fornecimento de alimento e sal 
Tabela 1 - Composição química, valores de energia bruta (kcal/kg MS), estimativa da proteína degradável (D) dos ingredientes, composição percentual e química das dietas (\%MS) e ingestão diária de proteína degradável (IPD) das dietas

Table 1 - Chemical composition, gross energy ( $k c a l / k g ~ D M)$, and estimated degradable protein (D) of ingredients, chemical and ingredient composition (\%DM) of diets, and daily ingestion of dietary degradable protein (IDP)

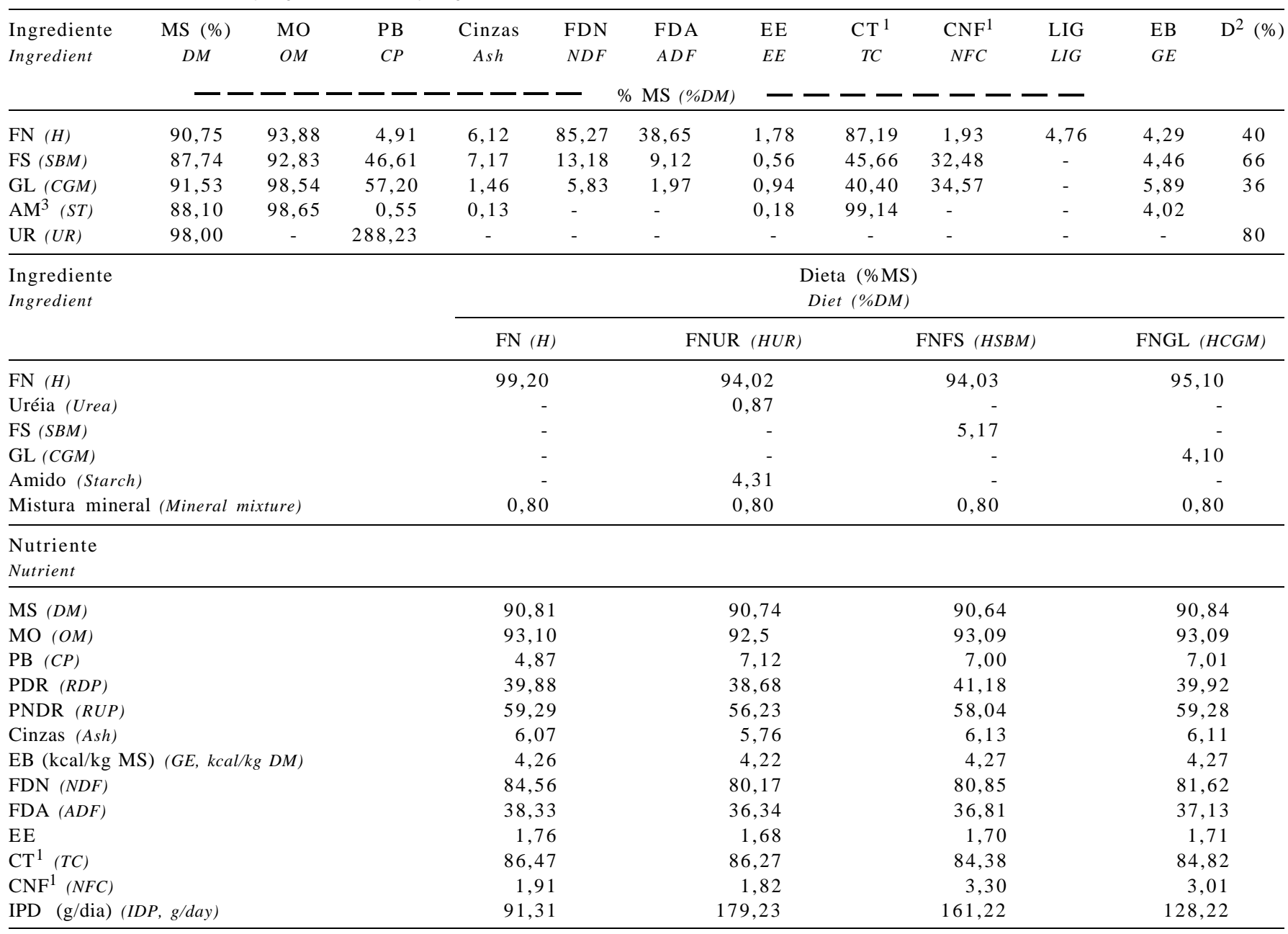

$\mathrm{FN}=$ feno de capim-tifton $85 ; \mathrm{FS}=$ farelo de soja; $\mathrm{GL}=$ glúten de milho $-60 ; \mathrm{AM}=$ amido; $\mathrm{UR}=$ uréia. $F N U R=\mathrm{FN}+$ uréia; FNFS = FN+farelo de soja; FNGL $=$ FN+glúten de milho-60.

${ }_{1} \mathrm{CT}=100-\left(\% \mathrm{~PB}+\% \mathrm{EE}+\%\right.$ cinzas) e CNF = CT - FDN (Sniffen et al., 1992); ${ }^{2}$ NRC (2001); ${ }^{3}$ Rostagno et al. (1992).

$H=$ Tifton-85 bermudagrass hay; $S B M=$ soybean meal; $C G M=60$ corn gluten meal; $S T=$ starch; $U R=$ urea.

${ }^{1} T C=100-(\% C P+\% E E+\%$ ash) and NFC $=$ TC-NDF (Sniffen et al., 1992).

mineral e para coleta de fezes. Para determinação da digestibilidade aparente no trato digestivo total, utilizou-se a coleta total de fezes. As amostras de fezes foram coletadas diariamente (7h) nas bandejas coletoras, sendo homogeneizadas e amostradas por animal e por período, em quantidade de aproximadamente $500 \mathrm{~g}$, sendo, então, congeladas até o término do período experimental, quando foram secas em estufa com circulação forçada, a $55^{\circ} \mathrm{C}$, durante 48 horas, e processadas em moinho com peneira $1 \mathrm{~mm}$ para formação de uma subamostra composta para análise dos nutrientes.

O consumo de alimento foi determinado diariamente, pesando-se (pela manhã) as sobras dos dias anteriores. Do 21 a a 24 o dia do período experimental, foram coletadas amostras de digesta duodenal, via cânula, para determinação da digestibilidade parcial. Foram realizadas três coletas por dia, a intervalos de oito horas, em intervalo de seis horas entre dias, a fim de que, no final de quatro dias, fossem obtidas 12 amostras de digesta duodenal por animal. O esquema foi o seguinte: dia 1 - coletas às 8,16 e 24h; dia 2 - coletas às 6,14 e 22h; dia 3 - coletas às 4,12 e 20h; e dia 4 - coleta às $2 ; 10 \mathrm{e} 18 \mathrm{~h}$.

As amostras foram armazenadas a $-5^{\circ} \mathrm{C}$ e, posteriormente, foram pré-secas em estufa ventilada $\left(\right.$ a $55^{\circ} \mathrm{C}$, por 72 a 96 horas), sendo trituradas em moinho com peneira de $2 \mathrm{~mm}$. Posteriormente, formou-se uma amostra composta por animal, em cada período de coleta, com base no peso seco de cada subamostra. As amostras compostas foram devidamente acondicionadas em recipientes e, posteriormente, submetidas a análises laboratoriais para determina- 
ção dos teores de MS, N total, FDN, FDA, cinzas, lignina e EE das amostras de fezes, digesta duodenal e dos componentes da ração, conforme metodologias descritas por Silva \& Queiroz (2002). Os teores de EB foram determinados em bomba calorimétrica adiabática PARR Instruments.

As digestibilidades e os fluxos diários de MS no duodeno foram determinados utilizando-se como indicador interno a fibra em detergente ácido indigestível (FDAi), obtida pelo método in vitro, após 144 horas de incubação (Berchielli et al., 2000). Para os cálculos de fluxo de MS duodenal, utilizou-se a equação descrita por Berchielli et al. (1998):

Fluxo de MS duodenal $=\frac{\text { MS fecal } \times \text { \% FDA indigestível na MS fecal }}{\% \text { FDA indigestível na MS duodenal }}$

Para a análise estatística dos resultados, adotou-se o delineamento experimental com dois quadrados latinos $4 \times 4$, com quatro animais, quatro tratamentos e quatro períodos experimentais. A análise de variância e a comparação de médias pelo teste Tukey a 5\% de significância foram obtidas pelo PROC GLM DO SAS (SAS, 1999).

\section{Resultados e Discussão}

Na Tabela 2 são apresentados os dados dos consumos médios dos nutrientes, em $\mathrm{kg} / \mathrm{dia}$ e em \% peso vivo (PV), e os respectivos coeficientes de variação. Os consumos de MS expressos nas diferentes formas não diferiram $(\mathrm{P}>0,05)$ entre os animais alimentados com as diferentes dietas, ou seja, a deficiência de PDR e/ou PB e as fontes de N não influenciaram a ingestão de MS, exceto para os nutrientes $\mathrm{PB}$ e CNF.

Estes resultados corroboram os obtidos por Cecava et al. (1990; 1991), Christensen et al. (1993), Dutra et al. (1997) e Branco et al. (2004) e são coerentes com os obtidos por Mertens (1994), que salientou a dificuldade de se estabelecer um mecanismo pelo qual o aumento da concentração de proteína resultasse em aumento da ingestão, sem incluir a teoria de regulação de energia.

Apesar do alto conteúdo de FDN do feno de tifton 85 (Tabela 1), o consumo de MS pelos animais foi elevado, provavelmente em virtude do menor grau de lignificação (lignina/FDN) da parede celular, pois os teores de lignina se mantiveram abaixo de $5 \%$ (Tabela 1), ou seja, 5,5\% daFDN, o que pode ter favorecido o consumo e a digestibilidade da forragem (Tabela 3). Além desse aspecto, o maior consumo de forragem também pode ser atribuído, em parte, ao menor tamanho das partículas do feno, pois foi
Tabela 2 - Consumo de nutrientes em novilhos alimentados com dietas formuladas com diferentes níveis de PDR

Table 2 - Intake of nutrients in steers fed diets with different ruminaldegradable protein levels

\begin{tabular}{|c|c|c|c|c|c|c|}
\hline \multirow[t]{2}{*}{$\begin{array}{l}\text { Nutriente } \\
\text { Nutrient }\end{array}$} & \multicolumn{4}{|c|}{$\begin{array}{l}\text { Dieta } \\
\text { Diet }\end{array}$} & \multirow[t]{2}{*}{$\begin{array}{l}\text { Média } \\
\text { Mean }\end{array}$} & \multirow[t]{2}{*}{$\mathrm{CV}(\%)$} \\
\hline & $\begin{array}{c}\mathrm{FN} \\
H\end{array}$ & $\begin{array}{c}\text { FNUR } \\
N P N\end{array}$ & $\begin{array}{l}\text { FNFS } \\
S B M\end{array}$ & $\begin{array}{c}\text { FNGL } \\
C G M\end{array}$ & & \\
\hline \multicolumn{7}{|c|}{ Consumo (kg/dia) } \\
\hline \multicolumn{7}{|c|}{ Intake ( $\mathrm{kg} /$ day) } \\
\hline $\operatorname{MS}(D M)$ & 4,69 & 4,70 & 4,81 & 4,65 & 4,71 & 16,11 \\
\hline MO (OM) & 4,35 & 4,34 & 4,46 & 4,31 & 4,37 & 16,34 \\
\hline $\mathrm{PB}(C P)$ & $0,25 b$ & $0,36 \mathrm{a}$ & $0,36 \mathrm{a}$ & $0,35 \mathrm{a}$ & 0,33 & 14,44 \\
\hline $\mathrm{EE}(E E)$ & 0,08 & 0,08 & 0,08 & 0,08 & 0,08 & 16,35 \\
\hline $\mathrm{CT}(T C)$ & 4,03 & 4,03 & 4,04 & 3,92 & 4,01 & 16,49 \\
\hline $\mathrm{FDN}(N D F)$ & 3,94 & 3,72 & 3,83 & 3,73 & 3,80 & 17,26 \\
\hline FDA $(A D F)$ & 1,79 & 1,66 & 1,70 & 1,73 & 1,72 & 17,32 \\
\hline $\mathrm{EB}(G E)$ & 0,20 & 0,20 & 0,20 & 0,20 & 0,20 & 16,52 \\
\hline $\mathrm{CNF}(N F C)$ & $0,09 \mathrm{c}$ & $0,09 \mathrm{bc}$ & $0,16 \mathrm{a}$ & $0,15 \mathrm{ab}$ & 0,12 & 33,98 \\
\hline \multicolumn{7}{|c|}{ Consumo (\% PV) } \\
\hline \multicolumn{7}{|c|}{ Intake (\% $B W)$} \\
\hline $\operatorname{MS}(D M)$ & 1,80 & 1,91 & 1,92 & 1,91 & 1,88 & 15,03 \\
\hline $\mathrm{MO}(O M)$ & 1,67 & 1,76 & 1,78 & 1,78 & 1,75 & 15,25 \\
\hline $\mathrm{PB}(C P)$ & $0,09 \mathrm{~b}$ & $0,15 \mathrm{a}$ & $0,15 \mathrm{a}$ & $0,15 \mathrm{a}$ & 0,13 & 13,92 \\
\hline $\mathrm{EE}(E E)$ & 0,03 & 0,03 & 0,03 & 0,03 & 0,03 & 15,95 \\
\hline CT (TC) & 1,55 & 1,63 & 1,62 & 1,62 & 1,60 & 15,37 \\
\hline FDN $(N D F)$ & 1,51 & 1,51 & 1,53 & 1,53 & 1,52 & 16,06 \\
\hline FDA $(A D F)$ & 0,71 & 0,67 & 0,69 & 0,74 & 0,70 & 16,06 \\
\hline $\mathrm{EB}(G E)$ & 0,08 & 0,08 & 0,08 & 0,08 & 0,08 & 15,60 \\
\hline CNF (NFC) & $0,04 \mathrm{~b}$ & $0,04 \mathrm{~b}$ & $0,07 \mathrm{a}$ & $0,06 a b$ & 0,05 & 41,07 \\
\hline
\end{tabular}

$F N=$ feno de tifton 85; FNUR = FN+uréia; FNFS = FN+farelo de soja FNGL $=\mathrm{FN}+$ glúten de milho- 60 .

Médias na mesma linha seguidas por letras distintas diferem $(P<0,05)$ pelo teste Tukey.

$H=$ Tifton -85 bermudagrass hay; $N P N=H+$ urea; $S B M=H+$ soybean meal; $C G M=H+60$ corngluten meal.

Means in the same row followed by different letters differ $(P<0.05)$ by Tukey test.

fornecido moído aos animais, permitindo maior amplitude de atuação dos microrganismos sobre a fibra, por oferecer menores impedimentos físicos à ação microbiana no rúmen, resultando em menor tempo de retenção do feno no rúmen, consequiência da digestibilidade dos componentes da fração fibrosa (Tabela 3).

A utilização de forrageiras de baixa qualidade, com teores de FDN superiores a $60 \%$ e teor de PB inferior a $6 \%$ pode reduzir o consumo, como resultado da baixa digestibilidade da fração fibrosa. Contudo, é necessário considerar que as folhas contêm altos teores de proteína, em virtude de sua alta concentração de rubisco (ribulose 1,5 difosfato), enzima fotossíntetica que compõe até 50\% da proteína solúvel nas folhas, mesmo que as folhas de gramíneas de clima tropical colhidas no estádio de desenvolvimento avançado apresentem altas proporções de feixes condutores na bainha vascular, dificultando o acesso até a rubisco, inserida dentro dessa bainha. No entanto, é pos- 
Tabela 3 - Digestibilidades total, ruminal e intestinal dos nutrientes em novilhos alimentados com dietas formuladas com diferentes níveis de PDR

Table 3 - Apparent total tract, ruminal, and intestinal digestibilities of nutrients in steers fed diets with different ruminal-degradable protein levels

\begin{tabular}{|c|c|c|c|c|c|c|}
\hline \multirow[t]{2}{*}{$\begin{array}{l}\text { Nutriente } \\
\text { Nutrient }\end{array}$} & \multicolumn{4}{|c|}{$\begin{array}{c}\text { Dieta } \\
\text { Diet }\end{array}$} & \multirow[t]{2}{*}{$\begin{array}{l}\text { Média } \\
\text { Mean }\end{array}$} & \multirow[t]{2}{*}{$\mathrm{CV}(\%)$} \\
\hline & $\begin{array}{c}\mathrm{FN} \\
H\end{array}$ & $\begin{array}{c}\text { FNUR } \\
N P N\end{array}$ & $\begin{array}{c}\text { FNFS } \\
S B M\end{array}$ & $\begin{array}{l}\text { FNGL } \\
C G M\end{array}$ & & \\
\hline \multicolumn{7}{|c|}{$\begin{array}{c}\text { Digestibilidade total }(\%) \\
\text { Total digestibility }(\%)\end{array}$} \\
\hline $\mathrm{MS}(D M)$ & 63,46 & 61,42 & 61,08 & 68,99 & 63,74 & 12,65 \\
\hline $\mathrm{MO}(O M)$ & 63,61 & 58,69 & 61,38 & 69,17 & 63,85 & 12,62 \\
\hline $\mathrm{PB}(C P)$ & $66,18 b$ & $76,69 a$ & $76,68 \mathrm{a}$ & $78,65 \mathrm{a}$ & 74,55 & 8,23 \\
\hline $\mathrm{CT}(T C)$ & 71,41 & 70,00 & 69,51 & 75,02 & 71,11 & 12,16 \\
\hline FDN $(N D F)$ & 64,80 & 59,96 & 60,42 & 68,95 & 63,53 & 13,09 \\
\hline FDA $(A D F)$ & $43,72 \mathrm{ab}$ & $41,42 b$ & $38,57 \mathrm{~b}$ & $55,48 \mathrm{a}$ & 44,80 & 9,63 \\
\hline $\mathrm{ED}(D E)$ & 62,23 & 59,74 & 60,81 & 68,13 & 62,73 & 12,96 \\
\hline & $\begin{array}{r}\text { Dig } \\
R\end{array}$ & $\begin{array}{l}\text { estibilida } \\
\text { uminal di }\end{array}$ & $\begin{array}{l}\text { de rumina } \\
\text { gestibility }\end{array}$ & (\%) & & \\
\hline $\mathrm{MS}(D M)$ & 57,72 & 59,43 & 60,23 & 60,15 & 59,38 & 4,90 \\
\hline $\mathrm{MO}(O M)$ & 64,50 & 64,17 & 66,13 & 65,99 & 65,19 & 4,02 \\
\hline $\mathrm{PB}^{1}(C P)$ & $-12,52 \mathrm{c}$ & $36,81 \mathrm{a}$ & $28,61 \mathrm{ab}$ & $16,86 \mathrm{~b}$ & 17,44 & 80,95 \\
\hline $\mathrm{CT}(T C)$ & 69,03 & 67,81 & 69,48 & 71,07 & 69,35 & 4,83 \\
\hline FDN $(N D F)$ & 77,77 & 71,20 & 76,47 & 75,17 & 75,15 & 6,76 \\
\hline FDA $(A D F)$ & 72,99 & 58,63 & 66,74 & 60,99 & 64,83 & 13,41 \\
\hline $\mathrm{ED}(D E)$ & 60,66 & 60,48 & 62,85 & 61,57 & 61,39 & 4,42 \\
\hline
\end{tabular}

Digestibilidade intestinal $(\%)$

$$
\text { Intestinal digestibility }(\%)
$$

$\begin{array}{llllllr}\text { MS (DM) } & 42,28 & 40,57 & 39,78 & 39,86 & 40,62 & 7,16 \\ \text { MO (OM) } & 35,51 & 35,84 & 33,88 & 34,01 & 34,81 & 7,54 \\ \text { PB }^{2}(C P) & 68,89 \mathrm{ab} & 61,08 \mathrm{~b} & 66,53 \mathrm{ab} & 74,81 \mathrm{a} & 67,83 & 9,98 \\ \text { CT (TC) } & 30,97 & 32,19 & 30,53 & 28,93 & 30,65 & 10,93 \\ \text { FDN (NDF) } & 22,23 & 28,80 & 23,53 & 24,83 & 24,85 & 20,44 \\ \text { FDA (ADF) } & 27,02 & 41,37 & 33,25 & 38,99 & 35,16 & 64,77 \\ \text { ED (DE) } & 39,35 & 39,52 & 37,15 & 38,43 & 38,61 & 7,02\end{array}$

FN = feno de tifton 85; FNUR = FN+uréia; FNFS = FN+farelo de soja; $\mathrm{FNGL}=\mathrm{FN}$ +glúten de milho- 60 .

$1=\%$ do ingerido, 2 = $\%$ do que chega ao duodeno

Médias na mesma linha, seguidas por letras diferentes diferem $(P<0,05)$ pelo teste Tukey.

$H=$ Tifton- 85 bermudagrass hay; $N P N=H+$ urea; $S B M=H+$ soybean meal; $C G M=H+60$ corngluten meal.

$1=\%$ intake, $2=\%$ duodenal flow of $C P$.

Means in the same row followed by different letters differ $(P<0.05)$ by Tukey test.

sível que a seletividade pelos animais tenha contribuído para a maior concentração de PB na dieta efetivamente ingerida (Van Soest, 1994). É importante salientar que, neste estudo, o feno foi oferecido aos animais com tamanho médio de partícula de $10 \mathrm{~cm}$, permitindo a seleção das partes mais nutritivas da planta, ou seja, as folhas. A importância das folhas no valor nutritivo e no consumo das forrageiras, as quais são rapidamente digeridas e degradadas no rúmen em relação aos colmos, foi evidenciada por Oliveira et al. (2000), que encontraram no capim-tifton 85 em idade de rebrota de 70 dias lâminas e caule com 10,3e 5,2\% de PB, 75,6 e 76,5\% de FDN, 37,75 e $44,77 \%$ de FDA, 5,15 e $10,77 \%$ de lignina e 50,1 e $44,8 \%$ de digestibilidade in vitro da MS, respectivamente.

A concentração de FDN na planta está associada ao espessamento da parede celular secundária e à menor fragilidade à raptura mecânica e à penetração microbiana, o que reduz a área superficial para o ataque microbiano (Mertens, 1993). Estudos realizados por Cabral et al. (2004) determinaram como principal fração dos carboidratos do feno de tifton 85 a fração $\mathrm{B}_{2}(51,20 \%)$, constituída de carboidratos fibrosos potencialmente digestíveis, de lenta taxa de degradação, que, juntamente com a fração C $(41,77 \%)$, indigestível, tende a afetar negativamente o consumo pelo enchimento ruminal e, conseqüentemente, o desempenho animal. Neste estudo, o consumo médio de FDN foi de 1,52\% $\mathrm{PV}$, indicando que a ingestão da dieta estaria sendo regulada principalmente pela limitação física do rúmen, visto que Mertens (1994) preconizou que a limitação por enchimento pode ser correlacionada ao teor de FDN da ração e propôs o valor médio de consumo de $1,2 \pm 0,1 \%$ do peso corporal em FDN como nível de consumo regulado por mecanismos físicos.

Considerando a baixa qualidade do feno e a baixa ingestão de protéina degradável (Tabela 1), pode-se afirmar que o consumo médio de MS não foi afetado pela deficiência de PDR e/ou PB, pois consumos semelhantes ou superiores foram encontrados na literatura, em estudos nos quais não havia deficiência de PDR e/ou PB na dieta.

Oliveira et al. (2004), avaliando diferentes tipos de camas de frango associadas à uréia na suplementação de novilhos consumindo capim-elefante Napier de baixa qualidade (4,7\% PB e 76,2\% FDN), obtiveram consumo similar de FDN (1,35\% PV). Os autores constataram que o consumo de proteína no suplemento não foi suficiente para acarretar efeito diferenciado na ingestão de MS da forragem e de MS total ou no consumo total de proteína, apesar de a suplementação protéica ter contribuído com até $32 \%$ de $\mathrm{PB}$ dos requerimentos nutricionais dos animais. Ítavo et al. (2002), utilizando o feno de tifton $85 \mathrm{em}$ diferentes relações volumoso:concentrado, encontraram consumo de FDN de até 1,8\% do peso corporal para bovinos Nelore na fase de cria.

Branco et al. (2004), trabalhando com dietas isonitrogenadas $(14,45 \% \mathrm{~PB})$ suplementadas com três fontes de proteína, uma de alta degradabilidade ruminal (farelo de soja - 71,18\% PDR), uma com proteína de baixa degradabilidade, de origem animal (farinha de penas - $66,36 \%$ PDR), e uma com baixa degradabilidade ruminal, de origem 
vegetal (farelo de glúten de milho - 66,23\% PDR), constataram que as exigências de $\mathrm{N}$ pelos microrganismos ruminais foram atendidas mesmo com a utilização de fontes de proteína de baixa degradabilidade, pois não houve influência das diferentes fontes na ingestão dos nutrientes. Ribeiro et al. (2001), em estudo com feno de tifton 85 em diferentes idades de rebrota, encontraram valores médios similares de ingestão, de 5,27 a $5,85 \mathrm{~kg} / \mathrm{dia}$, semelhantes aos obtidos por Cecava et al. (1990; 1991), Christensen et al. (1993), Dutra et al. (1997), Ladeira et al. (1999) e Signoretti et al. (1999).

Não houve diferença entre as fontes protéicas no consumo de PB expresso nas diferentes formas. No entanto, os animais alimentados apenas com feno apresentaram menores consumos de PB (Tabela 2). Apesar do consumo baixo de proteína pelos animais, a fermentação da fibra alimentar e o crescimento microbiano foram adequados, pois os teores de amônia mantiveram-se acima de $5 \mathrm{mg} / \mathrm{dL}$ (Silva et al., 2007), teor mínimo preconizado por Satter \& Slyter (1974) para a atividade dos microrganismos ruminais. Dutra et al. (1997), utilizando ração com farelo de soja ( $3,8 \%$ PDR) e farelo de glúten de milho- 60 + farelo de soja (0,8\% PDR), encontraram consumos de PB de 0,25 e 0,23\% PV, respectivamente, que não diferiram entre as fontes de $\mathrm{N}$ de diferentes degradabilidades.

O consumo reduzido de EE expresso nas diferentes formas pode ser explicado pela proporção elevada de volumoso na dieta, o que está de acordo com os resultados obtidos por Araújo et al. (1998) e Signoretti et al. (1999), que notaram declínio no consumo de EE à medida que aumentaram a quantidade de volumoso nas dietas.

Como demonstrado na Tabela 2, os animais apresentaram consumos semelhantes de carboidratos totais, dos componentes da fração fibrosa (FDN, FDA) e de energia bruta, expressos em diferentes formas. Os maiores consumos de carboidratos não-fibrosos foram observados nos animais alimentados com feno e farelo de soja e não diferiram $(\mathrm{P}>0,05)$ dos consumos obtidos com feno associado ao glúten de milho (Tabela 2).

Os valores referentes às digestibilidades aparentes totais, ruminal e intestinal dos nutrientes são apresentados na Tabela 3. Apesar da deficiência de PDR e/ou PB e da baixa qualidade do feno, os valores de digestibilidade dos nutrientes mantiveram-se na faixa descrita na literatura, indicando que a deficiência de PDR e/ou PB não afetou a digestibilidade da fibra, pois em todos os outros trabalhos revisados houve suplementação protéica e/ou fornecimento de volumoso de melhor qualidade. De acordo com Mathis et al. (2000), a suplementação protéica não tem efeito sobre a digestibilidade de forragens de baixa qualidade.
Cavalcante et al. (2004) encontraram digestibilidades de 70,5\% da MS, 70,2\% da PB, 72,0\% dos CT e 63,1\% da FDN ao utilizarem feno de tifton 85 com $6,0 \%$ de $\mathrm{PB}$ e $74,7 \%$ de FDN em dietas com 11,5\% de PB. Ribeiro et al. (2001), trabalhando também com feno de tifton 85 em diferentes idades de rebrota, registraram valores médios de digestibilidade aparente de MS, MO e PB de 70,9; 72,6 e $60 \%$, respectivamente.

Os altos valores de digestibilidade encontrados nas dietas experimentais, apesar da idade avançada do feno, podem ser atribuídos à taxa de $10 \%$ de sobras para ajuste do consumo das dietas ou do tamanho das partículas $(10 \mathrm{~cm})$, o que propiciou a seletividade dos animais sobre a dieta, resultando em maior consumo de folhas em relação aos caules do capim-tifton 85 (a proporção de caules nas sobras foi visivelmente maior). Além disso, como não foram considerados os valores dos nutrientes das sobras, pode ter ocorrido superestimativa da digestibilidade dos nutrientes das dietas.

Com base nessa teoria, presume-se que o valor nutritivo do ingerido neste experimento foi maior que o ofertado, o que pode ser comprovado pelo fato de os animais não terem perdido peso durante os períodos experimentais. Ressalta-se que, neste experimento, não foi contemplado o estudo da proporção caule/folhas do capim-tifton 85 e não foi analisada a composição química das sobras, as quais eram descartadas após a pesagem (os resultados da análise poderiam contribuir para a avaliação mais efetiva dos resultados obtidos). Outro fato importante é que, quando o consumo é baixo, a taxa de passagem diminui, ocorrendo maior retenção do alimento no rúmen, o que pode resultar em acréscimos na digestibilidade do alimento, altamente dependente do tempo que o alimento permanece no trato digestivo.

Além disso, nas condições desse experimento, o feno de capim-tifton 85 apresentou menores teores lignina (5,5\% do total da FDN, Tabela 1) em comparação a outras gramíneas tropicais e, como a lignina é um composto fenólico existente na parede celular considerada indigestível, esta menor concentração pode ser uma das possíveis causas dos altos valores de digestibilidade da parede celular (Tabela 3). De fato, os resultados descritos por Mandebvu et al. (1999) indicaram que a melhoria da digestibilidade e do desempenho animal com a utilização do capim-tifton 85 pode ser atribuída aos mais baixos teores de lignina e polissacarídeos interligados, além das mais baixas ocorrências de ferulatos éter ligados à lignina nessa gramínea. Verifica-se que os altos coeficientes de digestibilidade dos nutrientes, notadamente da fração FDN, corroboram vários trabalhos incluindo essa gramínea (Hill et al., 2001; Ribeiro et al., 2001). 
Comparando os valores de digestibilidade total da PB entre as dietas, verificou-se que não houve diferença entre as fontes de $\mathrm{N}$, no entanto, estes valores foram superiores $(\mathrm{P}<0,05)$ ao coeficiente de digestibilidade da dieta sem suplementação (Tabela 3 ).

Contudo, foram previstos menores valores de digestibilidade da $\mathrm{PB}$, visto que a digestibilidade da proteína é positivamente correlacionada ao teor de PB da forragem e a contribuição do $\mathrm{N}$ endógeno é maior, pois resulta da maior reciclagem de $\mathrm{N}$ decorrente da deficiência de PB nas dietas, principalmente daquela composta exclusivamente de feno. De acordo com o NRC (1985), o conteúdo de $\mathrm{N}$ reciclado está diretamente relacionado ao seu consumo, ou seja, animais que consomem $1 \%$ de $\mathrm{N}$ na MS podem reciclar $110,01 \%$ do $\mathrm{N}$ ingerido e aqueles que consomem $12 \%$ de $\mathrm{N}$ na MS ingerida reciclam apenas $24,16 \%$ do $\mathrm{N}$ ingerido. Por outro lado, segundo Van Soest (1994), menores ingestões de $\mathrm{N}$ promovem menores perdas de $\mathrm{N}$ fecal e urinária, o que pode ter contribuído para os elevados valores de digestibilidade da PB.

Uma hipótese para justificar também estes elevados valores está relacionada às características químicas do tifton 85, que possui relação FDN/lignina mais ampla, propiciando baixa resistência da parede celular à ação dos microrganismos.

Contrariando os resultados obtidos, Calvacante et al. (2005) preconizaram que o aumento nos níveis de PB nas dietas promove aumento na digestibilidade total da $\mathrm{PB}$ e estimaram incrementos na digestibilidade da PB de 3,14 unidades por unidade de acréscimo no nível de $\mathrm{PB}$ das dietas.

As diferenças nas digestibilidades ruminal e intestinal da PB estão coerentes com os resultados observados na literatura e podem ser atribuídas à variação na degradabilidade ruminal das fontes de proteína utilizadas neste ensaio.

Apesar da ausência de diferença entre as dietas suplementadas com as diferentes fontes $\mathrm{N}$, o coeficiente de digestibilidade da FDN na dieta contendo farelo de glúten de milho-60 foi 14,13\% superior ao do tratamento com farelo de soja e $15,00 \%$ superior ao da dieta contendo uréia como fonte de $\mathrm{N}$ (Tabela 3 ).

Souza et al. (2002) estudaram a interação de fontes protéicas de diferentes degradabilidades (alta versus baixa) e com altos e baixos teores de FDA (g/kg MS) e notaram que a digestibilidade da FDN no trato digestivo total quando utilizaram o farelo de glúten de milho- 60 nas dietas foi maior que quando utilizaram o farelo de soja ou a uréia. Araújo et al. (1998) observaram que a digestibilidade da FDN aumenta linearmente à medida que maiores proporções de volumoso são utilizadas nas dietas em relação a concentrados, o que poderia explicar os menores valores de digestibilidade ruminal $(\mathrm{P}<0,11)$ nas dietas FNUR, FNFS e FNGL quando comparadas à dieta sem suplementação.

Valores médios de digestibilidade total dos nutrientes semelhantes aos encontrados neste trabalho foram reportados por Ladeira et al. (1999) e Ribeiro et al. (2001). Valores inferiores foram descritos por Cabral et al. (2006), que também utilizaram feno de tifton $85 \mathrm{com} 5 \%$ PB. Cordes et al. (1998) constataram redução de $12 \%$ na digestibilidade do feno quando utilizaram suplementação com milho + uréia, no entanto, a utilização da suplementação com milho + farelo de glúten de milho-60 não modificou a digestibilidade do feno. Ausência de influência de diferentes fontes de $\mathrm{N}$ na digestibilidade dos nutrientes também foi relatada por Zeoula et al. (1999).

Todavia, Herrera-Saldana et al. (1990) observaram maiores digestibilidade da MS e PB quando alimentaram vacas multíparas no período intermediário de lactação com dieta contendo cevada e farelo de algodão como fontes de energia e proteína de degradação rápida no rúmen em comparação à dieta com milho e resíduo de cervejaria como fontes de energia e proteína de degradação lenta no rúmen ou à dieta com fonte de energia e proteína não-sincronizada no rúmen. Maiores digestibilidades aparentes da MS, PB e ED foram encontradas também por Zeoula et al. (1999), que compararam fontes de $\mathrm{N}$ de baixa (farinha de carne e ossos + farelo de algodão) e alta (farelo de canola + uréia) degradabilidade ruminal. Por outro lado, Cameron et al. (1991) notaram que a digestibilidade aparente da $\mathrm{PB}$ aumentou com o teor de $\mathrm{N}$ da ração.

Os valores médios de digestibilidade da PB das dietas foram superiores aos encontrados por Ladeira et al. (1999), de 67,27\%, e Ribeiro et al. (2001), de 60,0\%, utilizando feno de tifton 85. Foram similares, no entanto, ao encontrado por Cabral et al. (2006), de 73,45\%, também utilizando feno de tifton 85. Os valores médios negativos de digestibilidade ruminal (Tabela 3 ) na dieta contendo apenas feno indicam que a quantidade de $\mathrm{N}$ chegando ao duodeno foi maior que a ingerida, refletindo a reciclagem de $\mathrm{N}$ endógeno para o rúmen e demonstrando também que as perdas de $\mathrm{N}$ na forma de amônia no rúmen foram menores. Indicam ainda uma pequena deficiência dietética de proteína degradável no rúmen (Dutra et al., 1997; Ladeira et al., 1999; Ribeiro et al., 2001). Estes resultados podem ser comprovados também pelas menores concentrações de $\mathrm{N}-\mathrm{NH}_{3}$ no líquido ruminal dos animais recebendo esta dieta (Silva et al., 2007), refletindo utilização mais eficiente de $\mathrm{N}$ no rúmen dos animais recebendo esta dieta.

Esses valores negativos de digestibilidade da PB podem ser atribuídos à contribuição endógena proveniente de células epiteliais, enzimas e outros resíduos do abomaso 
e da reciclagem de $\mathrm{N}$ (Theurer et al., 2002). Evidenciando essa inferência, Mathis et al. (2000) compararam diferentes porcentagens de PDR em três forragens de baixa qualidade - Cynodon spp. (8,2\% de PB e $71 \%$ de FDN), Bromus spp. (5,9\% de PB e $65 \%$ de FDN) e feno de sorgo forrageiro (4,3\% de PB e 60\% de FDN) - e observaram que, a porcentagem de PDR para maximizar o consumo de MO digestível foi 8,2\% para Cynodon spp. 9,8\% para Bromus spp. e de 12,8\% para o sorgo forrageiro. Os autores apontaram a reciclagem de $\mathrm{N}$ como fator essencial para o pool de $\mathrm{N}$ degradado no rúmen. Portanto, a reciclagem é importante para manutenção dos níveis mínimos de $\mathrm{N}$ ruminal, principalmente quando a dieta possui baixa concentração de N (Mathis et al., 2000; Theurer et al., 2002).

Os valores de digestibilidade ruminal da $\mathrm{PB}$ das dietas FNUR, FNFS e FNGL (Tabela 3) demonstram que houve perdas ruminais de proteína como conseqüência do excesso de ingestão de PDR (Tabela 1) em relação à energia disponível no rúmen. Comparando as dietas, nota-se que, de modo geral, quanto maior a degradabilidade da PB, maior a perda de $\mathrm{N}$ dietético no rúmen, motivo pelo qual a dieta FNUR resultou em maior perda de $\mathrm{N}$ dietético no rúmen: pelo excesso de PDR ingerida ou pela falta de energia adequada para utilizar esta PDR, ou ainda, pela ausência de sincronização entre a degradação da proteína e a digestão de carboidratos (Souza et al., 2002).

Embora não tenha ocorrido diferença significativa na digestibilidade ruminal da FDN entre as dietas contendo as fontes de $\mathrm{N}$ de diferentes degradabilidades, verificou-se tendência $(\mathrm{P}<0,06)$ de menor digestibilidade ruminal na dieta contendo uréia como fonte de $\mathrm{N}$ em relação às dietas FNFS e FNGL, provavelmente em virtude do seu menor valor de degradação da FDN em relação às outras dietas (Silva et al., 2007).

Os valores de digestibilidade ruminal da FDN obtidos com a dieta sem suplementação (FN) foram mais altos $(\mathrm{P}<0,11)$, possivelmente porque a energia foi disponibilizada em pequenas quantidades para os microrganismos, o que aumentou a eficiência de aproveitamento do $\mathrm{N}$ no rúmen. Os coeficientes médios de digestibilidade intestinal da FDN indicam que houve alguma digestão da FDN no intestino grosso, como consequiência da presença de enzimas microbianas que digerem celulose e hemicelulose e são fermentadas por bactérias presentes nessa porção do intestino. Segundo Sniffen et al. (1992), a digestão da celulose e hemicelulose no intestino grosso pode variar de 18,5 a $49,5 \%$ e de 2,5 a $46 \%$ respectivamente.

Quando o N não-protéico (no caso a uréia) é ministrado a um animal com quantidade inadequada de $\mathrm{N}$ disponível no rúmen, o pico de amônia é alto, mas a produção de proteína microbiana é baixa, o que acarreta menores valores de digestibilidade ruminal (Souza et al., 2002). Por isso, pode-se afirmar que a sincronização de liberação de energia e a utilização de $\mathrm{N}$ nas dietas FNFS e FNGL foram maiores que na dieta FNUR, pois os animais desse tratamento tiveram ingestão de PDR mais alta (179,23 g/dia) em relação aos dos outros tratamentos, mas tenderam a apresentar menor digestibilidade ruminal da FDN. Do mesmo modo, a ausência de influência de diferentes fontes de $\mathrm{N}$ nas digestibilidades ruminal e intestinal da FDN foi relatada por Dutra et al. (1997).

Neste trabalho, a digestibilidade intestinal da FDA foi maior que a da FDN de todas as dietas avaliadas. Como a FDA faz parte da FDN, esses resultados podem ser atribuídos ao indicador utilizado, pois, de acordo com Berchielli et al. (1998), o indicador é um dos principais responsáveis pela grande variabilidade de resultados em estudos de digestibilidade.

\section{Conclusões}

A deficiência de $\mathrm{PB}$ ou as diferentes fontes de $\mathrm{N}$ na dieta não afetaram os consumos dos diferentes nutrientes, à exceção da $\mathrm{PB}$ e dos CNF.

A deficiência de PB não influenciou, à exceção da PB, as digestibilidade aparentes totais, ruminais e intestinais dos nutrientes. A digestibilidade aparente total da FDA foi influenciada pela deficiência de PB da dieta.

\section{Literatura Citada}

AGRICULTURAL AND FOOD RESEARCH COUNCIL - AFRC. Energy and protein requirement of ruminants. Wallingford: CAB International, 1993. 159p.

ARAÚJO, G.G.L.; COELHO DA SILVA, J.F.; VALADARES FILHO, S.C. et al. Consumo e digestibilidade total dos nutrientes de dietas contendo diferentes níveis de volumoso, em bezerros. Revista Brasileira de Zootecnia, v.27, n.2, p.345-354, 1998.

BERCHIELli, T.T.; ANDRADE, P.; FURLAN, C.L. Avaliação de indicadores internos em ensaios de digestibilidade. Revista Brasileira de Zootecnia, v.29, n.3, p.830-833, 2000

BERCHIELLI, T.T.; RODRIGUEZ, N.M.; OSÓRIO NETO, E. et al. Comparação de indicadores de fase sólida para medir fluxo de matéria seca e matéria orgânica no duodeno. Arquivo Brasileiro de Medicina Veterinária e Zootecnia, v.50, n.2, p.147-152, 1998 .

BRANCO, A.F.; MOURO, G.F.; HARMON, D.L. et al. Fontes de protéina, ingestão de alimentos e fluxo esplâncnico de nutrientes em ovinos. Revista Brasileira de Zootecnia, v.33, n.2, p.444452, 2004.

CABRAL, L.S.; VALADARES FILHO, S.C.; DETMANN, E. et al. Taxas de digestão das frações protéicas e de carboidratos para as silagens de milho e de capim-elefante, o feno de capimTifton 85 e o farelo de soja. Revista Brasileira de Zootecnia, v.33, n.6, p.1573-1580, 2004

CABRAL, L.S.; VALADARES FILHO, S.C.; DETMANN, E. et al Consumo e digestibilidade dos nutrientes em bovinos alimentados com dietas à base de volumosos tropicais. Revista Brasileira de Zootecnia, v.35, n.6, p.2406-2412, 2006. 
CAMERON, M.R.; KLUSMEYER, T.H.; LYNCH, G.L. et al. Effects of urea and starch on rumen fermentation, nutrient passage to the duodenum, and performance of cows. Journal of Dairy Science, v.74, n.4, p.1321-1336, 1991

CAVALCANTE, M.A.B.; PEREIRA, O.G.; VALADARES FILHO, S.C. et al. Níveis de proteína bruta em dietas para bovinos de corte: consumo e digestibilidades total e parcial dos nutrientes. Revista Brasileira de Zootecnia, v.34, n.6, p.2200-2208, 2005 (supl.)

CAVALCANTE, A.C.R.; PEREIRA, O.G.; VALADARES FILHO, S.C. et al. Dietas contendo silagem de milho (Zea maiz L.) e feno de capim-Tifton 85 (Cynodon spp.) em diferentes proporções para bovinos. Revista Brasileira de Zootecnia, v.33, n.6, p.2394-2402, 2004 (supl. 3).

CECAVA, M.J.; MERCHEN, N.R.; BERGER, L.L. et al. Effects of dietary energy level and protein source on nutrient digestion and ruminal nitrogen metabolism in steers. Journal of Animal Science, v.69, n.5, p.2230-2243, 1991.

CECAVA, M.J.; MERCHEN, N.R.; BERGER, L.L. et al. Intestinal supply of amino acids in sheep fed alkaline hydrogen peroxidetreated wheat straw-based diets supplemented with soybean meal or combinations of corn gluten meal and blood meal. Journal of Animal Science, v.68, n.2, p.467-477, 1990.

CHRISTENSEN, R.A.; CAMERON, M.R.; KLUSMEYER, T.H. et al. Influence of amount and degradability of dietary protein on production of milk components by lactating Holstein cows. Journal of Dairy Science, v.76, n.11, p.3497-3513, 1993.

COELHO DA SILVA, J.F.; LEÃO, M.I. Fundamentos de nutrição de ruminantes. Piracicaba: Livroceres, 1979. 380p.

CORDES, C.S.; TURNER, K.E.; PATERSON. J.A. et al. Corn gluten feed supplementation of grass hay diets for beef cows and yearling heifers. Journal of Animal Science, v.66, n.2, p.522531,1988

DUTRA, A.R.; QUEIROZ, A.C.; PEREIRA, J.C. et al. Efeitos dos níveis de fibra e das fontes de proteínas sobre o consumo e digestão dos nutrientes em novilhos. Revista Brasileira de Zootecnia, v.26, n.4, p.787-796, 1997.

HERRERA-SALDANA, R.; GOMEZ-ALARCON, R.; TORABI, M. et al. Influence of synchronizing protein and starch degradation in rumen on nutrient utilization and microbial synthesis. Journal of Dairy Science, v.73, n.1, p.142-148, 1990.

HILL, G.M.; GATES, R.N.; WEST, J.W. Advances in bermudagrass research involving new cultivars for beef and dairy production. Journal of Animal Science, v.79, p.E48-E58, 2001 (E suppl.).

ÍTAVO, L.C.V.; VALADARES FILHO, S.C.; SILVA, F.F. et al. Níveis de concentrado e protéina bruta na dieta de bovinos Nelore nas fases de cria e terminação: consumo e digestibilidade. Revista Brasileira de Zootecnia, v.31, n.2, p.1033-1042, 2002 (supl.)

LADEIRA, M.M.; VALADARES FILHO, S.C.; COELHO DA SILVA, J.F. et al. Consumo e digestibilidades aparentes totais e parciais de dietas contendo diferentes níveis de concentrado, em novilhos nelore. Revista Brasileira de Zootecnia, v.28, n.2, p. 395-403, 1999.

MANDEBVU, P.; WEST, J.W.; HILL, G.M. et al. Comparison of Tifton 85 and Coastal Bermudagrasses for yield, nutrient traits, intake, and digestion by growing beef steers. Journal of Animal Science, v.77, n.6, p.1572-1586, 1999.

MATHIS, C.P.; COCHRAN, R.C.; HELDT, J.S. et al. Effects of supplemental degradable intake protein on utilization of medium- to low quality forages. Journal of Animal Science, v.78, n.1, p.224-232, 2000.

MERTENS, D.R. Regulation of forage intake. In: FAHEY JR., G.C.; COLLINS, M.; MERTEN, D.R. et al. (Eds.). Forage quality evaluation and utilization. Madison: America Society of Agronomy; Crop Science Society of America; Soil Science Society America, 1994. p.450-493.
MERTENS, D.R. Kinetics of cell wall digestion and passage in ruminant. In: JUNG, H.G.; BUXTON, D.R.; HATIFIELD, R.D. et al. (Eds.). Forage cell wall structure and digestibility. Madison: America Society of Agronomy; Crop Science Society of America; Soil Science Society America, 1993. p.535-570.

NATIONAL RESEARCH COUNCIL - NRC. Nutrient requirements of dairy cattle. 7. rev. ed. Washington, D.C.: National Academy of Science, 2001. 381p.

NATIONAL RESEARCH COUNCIL - NRC. Ruminant nitrogen usage. Washington, D.C.: National Academy of Science, 1985. 138p.

OLIVEIRA, M.A.; PEREIRA, O.G.; GARCIA, R. et al. Rendimento e valor nutritivo do capim-Tifton 85 (Cynodon spp.) em diferentes idades de rebrota. Revista Brasileira de Zootecnia, v.29, n.6, p.1949-1960, 2000 (supl. 1).

OLIVEIRA, R.V.; LANA, R.P.; MALDONADO, F. et al. Avaliação de diferentes tipos de camas de frango, associadas à uréia, na suplementação de novilhos consumindo forragem de baixa qualidade. Revista Brasileira de Zootecnia, v.33, n.2, p.471480,2004

RIBEIRO, K.G.; PEREIRA, O.G.; GARCIA, R. et al. Consumo e digestibilidades aparentes total e parcial de nutrientes, em bovinos recebendo rações contendo feno de capim-Tifton 85 de diferentes idades de rebrota. Revista Brasileira de Zootecnia, v.30, n.2, p.573-580, 2001.

ROSTAGNO, H.S.; SILVA, D.J.; COSTA, P.M.A. et al. Composição de alimentos e exigências nutricionais de aves e suínos. Viçosa, MG: Universidade Federal de Viçosa, 1992. 60p.

SATTER, L.D., SLYTER, L.L. Effect of ammonia concentration on rumen microbial protein production in vitro. British Journal of Nutrition, v.32, p.199-205, 1974.

STATISTICAL ANALYSIS SYSTEM - SAS. SAS system: SAS/ STAT. version 8.0. Cary: 1999. (CD-ROM).

SIGNORETTI, R.D.; COELHO DA SILVA, J.F.; VALADARES FILHO, S.C. et al. Consumo e digestibilidade aparente em bezerros da raça Holandesa alimentados com dietas contendo diferentes níveis de volumosos. Revista Brasileira de Zootecnia, v.28, n.1, p.169-177, 1999.

SILVA, D.J.; QUEIROZ, A.C. Análise de alimentos (métodos químicos e biológicos). 3.ed. Viçosa: Editora UFV, 2002. 235p.

SNIFFEN, C.J.; O'CONNOR, J.D.; Van SOEST, P.J. et al. A net carbohydrate and protein system for evaluation cattle diets. II. Carbohydrate and protein availability. Journal of Animal Science, v.70, n.11, p.3562-3577, 1992.

SOUZA, M.A.; EZEQUIEL, J.M.B.; ROSSI JR., P. et al. Efeitos de fontes nitrogenadas com distintas degradabilidades sobre o aproveitamento da fibra, do nitrogênio e do amido em rações para bovinos. Revista Brasileira de Zootecnia, v.31, n.5, p.2139-2148, 2002

THEURER, C.B.; HUNTINGTTON, G.B.; HUBER, J.T. et al. Net absorption and utilization of nitrogenous compounds across ruminal, intestinal, and hepatic tissues of growing beef steers fed dry-rolled or steam-flaked sorghum grain. Journal of Animal Science, v.80, n.2, p.525-532, 2002.

Van SOEST, P.J. Nutritional ecology of ruminant. New York: Cornell, Ithaca. Comstock Publishing Associates. 1994. 476p.

ZEOULA, L.M.; PRADO, I.N.; CECATO, U. et al. Valor nutritivo de rações compostas de fontes de amido e de nitrogênio com alta e baixa degradabilidade ruminal. Revista Brasileira de Zootecnia, v.28, n.5, p.1159-1167, 1999.

SILVA, E.A.; BERCHIELLI, T.T.; REIS, R.A. et al. Teores de proteína bruta para bovinos alimentados com feno de capim-tifton 85 : parâmetros ruminais, eficiência de síntese microbiana e degradabilidade in situ. Revista Brasileira de Zootecnia, v.36, n.1, p.225-236, 2007.

Recebido: 03/10/05 Aprovado: 16/08/06 